\section{On-grid batteries for large-scale energy storage: Challenges and opportunities for policy and technology}

Thomas A. Faunce, College of Medicine, Biology and the Environment, and Law School, Energy Change Institute, Australian National University, Canberra, ACT 2601, Australia

James Prest, Law School and Energy Change Institute, Australian National University, Canberra, ACT 2601, Australia

Dawei Su, School of Mathematical and Physical Sciences, Faculty of Science, and Centre for Clean Energy Technology, University of Technology, Sydney, NSW 2007, Australia

Sean J. Hearne, Center for Integrated Nanotechnologies, Sandia National Laboratories, Albuquerque, NM 87185-1304, USA

Francesca lacopi, School of Electrical and Data Engineering, Faculty of Engineering and IT, and Centre for Clean Energy Technology, University of Technology, Sydney, NSW 2007, Australia

Address all correspondence to Francesca lacopi at Francesca.lacopi@uts.edu.au (Received 8 February 2018; accepted 26 July 2018)

\title{
ABSTRACT
}

We offer a cross section of the numerous challenges and opportunities associated with the integration of large-scale battery storage of renewable energy for the electric grid. These challenges range beyond scientific and technical issues, to policy issues, and even social challenges associated with the transition to a more sustainable energy landscape.

The commissioning on 1 December 2017 of the Tesla-Neoen 100 MW lithium-ion grid support battery at Neoen's Hornsdale wind farm in South Australia, at the time the world's largest, has focused the attention of policy makers and energy professionals on the broader prospects for renewable energy storage. An adequate and resilient infrastructure for large-scale grid scale and grid-edge renewable energy storage for electricity production and delivery, either localized or distributed, is a crucial requirement for transitioning to complete reliance on environmentally protective human energy systems. Its realization will require a strong synergy between technological advances in variable renewable energy storage and the governance policies that promote and support them. We examine how existing regulations and governance policies focusing on large-scale batteries have responded to this challenge around the world. We offer suggestions for potential regulatory and governance reform to encourage investment in large-scale battery storage infrastructure for renewable energy, enhance the strengths, and mitigate risks and weaknesses of battery systems, including facilitating the development of alternatives such as hybrid systems and eventually the uptake of hydrogen fuel and storage.

Keywords: energy storage; renewable energy; battery storage; regulation; governance

\section{DISCUSSION POINTS}

- Are battery energy storage systems the solution to variable renewable energy?

- How can policies help transition toward large-scale energy storage and should they do so?

- What are the societal impacts of implementing large-scale Li-ion batteries?

\section{Introduction}

A sound infrastructure for large-scale energy storage for electricity production and delivery, either localized or distributed, is a crucial requirement for transitioning to complete reliance on environmentally protective renewable energies. Its realization requires synergy between technological advances, governance policies, and environmental ethics. ${ }^{1,2}$ Global warming and large-scale pollution generated by conventional oil, coal, and natural gas fossil fuel (probably more accurately described as 'archived photosynthesis') sources have led the 
international community to attempt curbing carbon emissions as recommended by the Intergovernmental Panel on Climate Change; as a result 173 nations have ratified the United Nations Paris Agreement. ${ }^{3}$

Whether in response to this global challenge, or simply thanks to the foresight of local administration, renewable energies are currently contributing a rapidly growing percentage of electricity generation through microgrids or large-scale grids in many regions around the world. ${ }^{4,5}$ Some regions are blessed with a geography allowing for large-scale implementation of hydropower, a few others have invested in biomass as alternative largescale energy source. Many, however, focus more on variable renewable energy (RE) sources such as solar and wind, which are becoming a prominent slice of the grid energy portfolio in most countries. In 2014, the International Energy Agency (IEA) estimated that at least an additional $310 \mathrm{GW}$ of grid connected energy storage will be required in four main markets (China, India, the European Union, and the United States) to achieve its Two Degrees Scenario of energy transition. ${ }^{6}$ As a consequence, smart grids and a variety of energy storage solutions are becoming central to the efficient and reliable management and distribution of energy. It is important, for example, to distinguish grid scale or grid edge battery storage systems. In addition, the choice of energy storage technology will depend on which services the storage will provide-addressing local short temporal imbalances, or regional imbalances, or rather seasonal imbalances.

\section{The promise of large-scale batteries}

Poor cost-effectiveness has been a major problem for electricity bulk battery storage systems. ${ }^{7}$ Now, however, the price of battery storage has fallen dramatically and use of large battery systems has increased. According to the IEA, while the total capacity additions of nonpumped hydro utility-scale energy storage grew to slightly over $500 \mathrm{MW}$ in 2016 (below the 2015 growth rate), nearly $1 \mathrm{GW}$ of new utility-scale stationary energy storage capacity was announced in the second half of 2016; the vast majority involving lithium-ion batteries. ${ }^{8}$ Regulatory uncertainty has been a major factor holding back even greater use of large battery storage by electricity grid operators. ${ }^{9,10}$

The International Panel on Climate Change's (IPCC's) Special Report on Renewable Energy Sources and Climate Change Mitigation (SRREN) (Date 2011) likewise noted that increased market penetration of partially dispatchable RE technologies (wind, solar PV, certain forms of ocean energy) will require variable capture renewable generators to become more active participants in maintaining the stability of the grid during power system contingencies. ${ }^{11}$ Modifications to institutional and governance frameworks are necessary and not only for dealing with the intermittency and variability of some RE sources. This article intends to address such gaps.

\section{Storage case study: South Australia}

In 2017, large-scale wind power and rooftop solar PV in combination provided $57 \%$ of South Australian electricity generation, according to the Australian Energy Regulator's State of the
Energy Market report. ${ }^{12}$ This contrasted markedly with the situation in other Australian states such as Victoria, New South Wales, and Queensland which were heavily reliant on brown and black coal for electricity generation. ${ }^{13}$ In that year, however, an intense storm caused an extended major blackout in electricity supply by disrupting grid access to the Australian National Electricity market (NEM). ${ }^{14}$ The issue became highly debated on the political scene, with some politicians supporting false claims by coal industry acolytes that reliance on RE inevitably would compromise reliability and security of energy supply. ${ }^{15}$

South Australia, a jurisdiction blessed with abundant windsourced RE, became an important case study in this context. In July 2017, the South Australian Government and entrepreneur Elon Musk announced a partnership-to build the "world biggest battery' to stabilize that state's electricity grid. The 129 MW h lithium-ion battery is linked to the Hornsdale wind farm near Jamestown, $200 \mathrm{~km}$ north of Adelaide, and was developed as a co-venture between Tesla and French wind-farm developer Neoen. ${ }^{16}$ The project crystallized attention on the idea of large-scale battery storage for variable RE supply. The battery was completed in November, achieved start-up in December 2017, and has since operated successfully. ${ }^{17}$

Several other large-scale battery projects were completed in Australia in 2016 including the 2 MW h installation at the Sand re Resources Copper Mine and the 1.1 MW h community installation at Alkimos Beach in Western Australia. ${ }^{16}$ Another more radical approach involves attempting to use cloud-based software in South Australia to remotely access and aggregate home-based battery storage systems. ${ }^{13}$ A related plan involved creating a virtual 'big battery' through the donation of 50,000 T batteries to South Australian homes. ${ }^{18}$ As a whole, however, Australia lags behind in terms of the electricity grid percentage contribution of RE versus fossil fuel sources; therefore, the extent of success of the South Australian choice will have important national and international policy and technology implications. ${ }^{13}$

But how should we best assess whether the Musk model of using Li-ion bulk battery energy storage to enable variable RE inputs (i.e., wind, solar, and tidal) is suitable for reliable and affordable energy on a global scale? There is much at stake in this assessment, given that variable renewable input to 'smart' electricity grids is rapidly increasing worldwide and PV is tipped to expend to the terawatt scale of generation. ${ }^{19}$

The South Australian large-scale battery represents a growing trend. Other nations have installed large lithium-ion batteries and sodium sulfur batteries to 'stabilize' variable RE inputs to their electricity grids (Japan - Buzen - 300 MW h, 50 MW; USA Escondido $30 \mathrm{MW} \times 4 \mathrm{~h}=120 \mathrm{MW} \mathrm{h}^{20}$ ). Research by the Global Alliance of Solar Energy Research Institutes argues that to reach 5 to 10 TW of PV installed globally by 2030, apart from ongoing cost reductions in PV technologies, there is an urgent need for more flexible grids that can more readily accommodate more PV generated electricity. ${ }^{21}$ Storage problems already have resulted in the periodic curtailment of PV generated electricity in California. ${ }^{22}$ Can big battery storage prevent renewably

2 - MRS ENERGY \& SUSTAINABILITY // VOLUME 5 // e11 // www.mrs.org/energy-sustainability-journal 
generated electricity from being wasted through curtailment? Research in China has examined policies as well as potential for increased energy storage capacity to prevent similar curtailment in renewable electricity. ${ }^{23,24}$ In 2012 and 2013, for example, nearly 17.1 and $10.7 \%$ of the total wind power available from China's wind systems were curtailed resulting in estimated financial losses of 1.72 and 1.41 billion US dollars. ${ }^{24}$

\section{Battery energy storage systems (BESS)}

\section{Large-scale BESS}

The idea of using battery energy storage systems (BESS) to cover primary control reserve in electricity grids first emerged in the 1980s. ${ }^{25}$ Notable examples since have included BESS units in Berlin, ${ }^{26}$ Lausanne, ${ }^{27}$ Jeju Island in South Korea, ${ }^{28}$ and other small island systems. ${ }^{29,30}$ One review of realized or planned BESSs for ancillary service provision showed an average capacity of more than 4 MW h per BESS. ${ }^{10}$

One BESS system gaining popularity involves a bank of lithium-ion batteries with bidirectional converters that can absorb or inject active or reactive power at designated set points through a power conversion system (PCS) to the electricity grid along with a battery management system (BMS) to monitor battery condition and charge rate as well as estimate the amount of usable electrical energy stored in the battery pack. ${ }^{31}$ Benefits of BESS units include capacity to rapidly compensate for peak loading with a high energy demand that causes a slight change in frequency, ramp control, and capacity firming when output drops (i.e., wind falls or clouds come over). The compensation is accomplished by supplying an adjustable range of real or reactive power, replacing spinning reserve capacity to cope with generator failure or unexpected transmission loss, enhanced capacity to bootstrap after a blackout and/or loss of generation capacity, storage of low-cost power and capacity to level out power flow and delay costly upgrades. ${ }^{2}$

Additional applications of big battery RE storage technologies include the following: (i) reducing the need for "peaking plants' (high-cost, highly responsive fossil-fuel powered plants that can be used to meet peak loads); and (ii) deferring the need for costly upgrading and augmentation of transmission and distribution networks to improve their ability to handling peak loads. There are, however, different grid dynamics depending on whether the RE generation and big battery storage is distributed or centralized. When distributed generation is combined with distributed storage, it 'knocks off the peak' because, from a whole-grid perspective, it is the equivalent of a reduction in demand. The demand peak still occurs but it is supplied by small generators and storage units that are outside of the control of market operator. Ideally, this would translate into a reduced need for peaking oil and coal plants and reduced need for the network to carry the peak load. However, a distributed generation and storage system would have limited capacity to respond in real time and in a coordinated fashion to larger-scale load trends; hence, a preferred approach would be the combination of distributed energy storage technologies with a centrally directed decision system.
The environmental impacts of BESS systems during operation compare favorably to coal-powered systems for primary control provision. ${ }^{32}$ Compared to coal-powered systems, BESS approaches have most adverse environmental impacts during construction, but even then have lower environmental impacts in all major categories (i.e., global warming potential, acidification potential, ozone depletion potential, eutrophication potential (freshwater and saltwater) human toxicity potential (carcinogen and noncarcinogen) eco-toxicity potential) except abiotic resource depletion due to scarcity of mineral resources. ${ }^{33}$

\section{Why lithium-ion: battery technologies and new alternatives}

Lead-acid batteries, a precipitation-dissolution system, have been for long time the dominant technology for large-scale rechargeable batteries. However, their heavy weight, low energy and power densities, low reliability, and heavy ecological impact have prompted the development of novel battery technologies. Lithium-ion components tend to be the dominant feature of BESS approaches, as they currently represent the best compromise between market readiness, cost, lifetime, and energy density. ${ }^{34,35}$ Lithium-ion technologies have been the major breakthrough in the area of electrochemical energy storage in recent times. ${ }^{36}$

Redox reactions are central to the operation of Li-ion batteries, with lithium being an extremely efficient reducing element and also one of the most reactive. Progressive development has led to the use of the safer lithium compounds $\left(\mathrm{LiCoO}_{2}\right.$, $\mathrm{LiNi}_{1 / 3} \mathrm{Co}_{1 / 3} \mathrm{Mn}_{1 / 3}, \mathrm{LiFePO}_{4}, \mathrm{LiMn}_{2} \mathrm{O}_{4}$, etc.) as the cathode, improved electrolytes with lower amounts of volatile compounds and high decomposition voltage window. ${ }^{37}$ Equally important has been the creation of the specific composite graphitic carbon as the anode (opposed to pure lithium). Key to the efficiency of modern Li-ion technologies is the reversible intercalation of $\mathrm{Li}^{+}$ions between the cathode and anode, allowing the recharging of a Li-ion battery with satisfactory efficiency.

One crucial parameter for batteries is their specific energy density, reported either in gravimetric (W h/ kg) or volumetric (W h/L) units. Typical energy densities obtained with Li-ion batteries are around 250-300 W h/kg. ${ }^{38}$ While not yet ideal (batteries are still heavy and they represent a substantial \% weight in a portable or automotive system), they are much better in this context than any previous RE storage technology. Due to the complexity of optimizing the various fundamental parameters involved in the efficiency of a battery, which include (i) electron conductivity, (ii) $\mathrm{Li}^{+}$ion conductivity, and (iii) the $\mathrm{Li}^{+}$ion intercalation related phase transformations, the energy density of electrochemical batteries has only improved at less than $10 \%$ per year (much less, e.g., than the exponential progress in computational power typical of electronics). ${ }^{39}$

Recent advances in materials design and nanotechnology are opening new avenues to further improve batteries as RE storage systems. The engineering of nanostructured composite materials, for example, offers new avenues to maximize the surface area and accessibility of the active and host materials while maintaining overall high electronic conductivity, which is key 
to higher energy densities. The cathode material for Li-ion batteries also strongly relies on the advanced nanostructuring of conductive carbon composites for improving reversible $\mathrm{Li}^{+}$ion intercalation and electron conductivity. ${ }^{40}$

In addition to Li-ion technologies, which are already commercial, a large research effort is focusing on alternate metal-ion technologies to reduce the cost from Li metal and enhance energy densities, such as Na-ion and K-ion, ${ }^{41}$ cheaper but shorter lifetime and lower energy density, as well as $\mathrm{Mg-ion}{ }^{42}$ and $\mathrm{Al}$-ion, ${ }^{43}$ safer, cheaper, higher densities but low cyclability. All these alternate charge-carrier ions have promises and challenges compared to their lithium counterpart.

Another route for the improvement of energy densities and lower cost focuses on the search for new chemistries between charge-carrier ions and host materials beyond the conventional 'intercalation' mechanisms with relatively small number of crystallographic sites for storing charge-carrier ions. ${ }^{3}$ An opportunity is offered by Li-S (and corresponding Na-S) battery technologies, where each sulfur atom at the cathode can host 2 lithium ions, as compared to the typical $0.5-0.7$ for the more conventional Li-ion batteries. This advantage is offset by a reduced electrode conductivity at the cathode site. Current lines of research see the tailoring of porous structured carbon to suit sulfur cathodes. ${ }^{44}$

One alternative technology aimed at the improvement of energy density involves the more controversial metal-air batteries. In this approach, one of the electrodes is replaced by "air" or in fact oxygen flow, which clearly makes the whole unit much lighter. However, in addition to higher charging voltage needed for operation, higher electrode instabilities, and potentially also higher safety concerns, a lot of fundamental questions still need to be addressed in the metal-air technology, while some more detailed understanding was recently offered by a group from MIT. ${ }^{45}$

Finally, a non-solid-state technology route for scaling up to very large units/volumes, involves redox-flow batteries. This alternate rechargeable technology is based on electrochemically active compounds dissolved in a liquid form as separate anolyte and catholyte; the amount of energy stored is directly related to the size of the liquid tank stack. Vanadium flow batteries are the most promising alternative to the Tesla/Li-ion battery technology for BESS. Although the energy density of redox-flow batteries is usually lower than Li-ion, they can deliver high cyclability and higher power densities. ${ }^{46}$ Flow batteries also decouple power density from energy density allowing system optimization for the application, providing cost saving over conventional batteries.

\section{Limitations of lithium-ion-based BESS}

If Li-ion BESS units of the type planned by Tesla for South Australia were to become globally utilized, operational concerns include rate capability, cost and lifetimes, efficiency, as well as safety and positive environmental and social life cycle analysis. ${ }^{2}$

As discussed, one of the most important parameters for batteries is the maximum achievable energy density per unit volume or weight. Solid-state batteries provide a high energy density but unfortunately a relatively low power density because of their slow charge/discharge rate, which limits the maximum current and power extractable from such a system at any given time. This effect is well-represented graphically in a Ragone plot, where the $y$-axis indicates the energy density ( $\mathrm{Wh} / \mathrm{kg}$ ) and the $x$-axis indicates the power density of a storage unit (Fig. 1). Li-ion batteries do not extend beyond power densities of $300 \mathrm{~W} / \mathrm{kg} .{ }^{38}$ This is an important consideration as it affects directing the handling of the peak-load of grids: although the total energy autonomy may be large enough to avoid blackouts, the lack of fast response of the units to peak-loads may still make the system susceptible to intermittencies.

\section{Lifetime and safety concerns}

Inevitably, the structural changes arising from volume expansion and shrinkage during $\mathrm{Li}^{+}$ion intercalation and de-intercalation, which are the basis of the battery operation (charge and discharge), will lead to performance loss upon cycling as some of the $\mathrm{Li}^{+}$ions will not be $100 \%$ reversible. ${ }^{39} \mathrm{In}$ addition, the degradation of the electrolyte as well as the formation of irreversible solid-state electrolyte interfaces over time also contribute to a degradation of battery performance. ${ }^{48}$

Another drawback of Li-ion solid-state batteries is their ultimate cyclability and calendar life. Some of the main issues are as follows: (i) a gradual but continuous loss in capacity retention

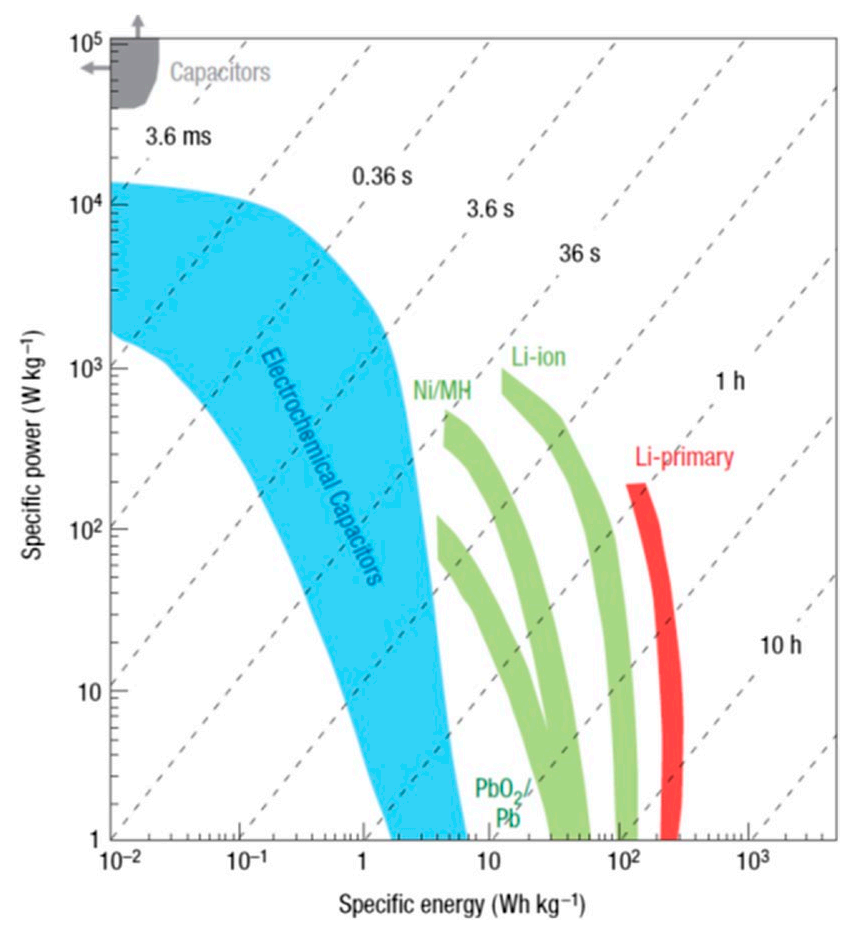

Figure 1. Ragone plot related to specific energy and power of typical electrochemical capacitors compared with other electrochemical energy storage systems. Reproduced with permission of the Nature Publishing Group. ${ }^{47}$ 
upon cycling (cycle life), which is exacerbated if the batteries at any point during their operation become completely or close to completely discharged, hence the need for a protection to avoid full depletion, (ii) a limited shelf-life (calendar life), even when the batteries are not being used, and, (iii) finally, prolonged exposure to heat reduces the battery lifetime. The latter is a particularly important issue in regions subject to high temperatures over prolonged periods, such as South Australia.

With conservative operation, Li-ion batteries can sustain relatively long operation. ${ }^{49}$ The ultimate lifetime of a battery is crucially determined by its mode of operation and is typically reported to vary within a large range between a few to above 10 years, and the prediction of remaining useful time of a battery is quite complex. ${ }^{50}$

A BMS is usually put in place for ensuring battery packs only operate in a region of parameters of current, temperature, and voltage where degradation is minimal and lifetime is extended to the maximum. Clearly, the definition of the optimal region of operation needs to take also into account the ultimate purpose of the batteries (whether, e.g., high power is demanded) and their physical location.

An appropriate BMS is also critical for safety reasons. Li-ion batteries being very energetic (particularly the lithium cobalt oxide cathode) and involving strongly exothermic processes, any accidental short-circuit could lead to fast heating and potential fire ignition that could extend to adjacent cells. A fire originating from batteries in addition has to be treated with very specific provisions to avoid catastrophic consequences.

Short-circuits can be potentially caused by punctured separator membranes, either as a fault at fabrication (hence the crucial importance of rigorous production quality control) or as a result of erroneous or dangerous/unprotected operation. Redundant layers of safety, especially for large capacity systems such as BESS, are certainly advisable. Specifically, in Australia, the standards committee has been proposing a particularly conservative stand in the approach of high capacity battery systems and their use for example in residential units. ${ }^{51}$

These issues combined with the rapidly expanding array of new battery materials systems, and continual evolution of deployment strategies, have resulted in a lack of long-term field measurements of overall system lifetimes. ${ }^{52}$ Without long-term data, utilities are reluctant to deploy new technologies as the overarching regulatory structure imposed on them drives risk aversion.

\section{Sourcing of raw materials}

The carbon footprint per lithium ion battery is estimated to be $70 \mathrm{~kg} \mathrm{CO}_{2}$ per $\mathrm{kW} \mathrm{h.}{ }^{9}$ As the Gigafactory and smaller competing companies in the space are striving to obtain a quasizero-carbon-footprint for battery production by using a substantial amount of renewable energies, ${ }^{53}$ this parameter may not be necessarily considered a major bottleneck.

Conversely, the likelihood of lithium-ion batteries becoming a ubiquitous means of large scale energy storage is reduced by the fact that many of their main components such as lithium and cobalt that are relatively scarce compared to a global scale demand and are being often mined from ores in conflict zones, creating a highly problematic human rights and environmental provenance. $^{15}$

Goldman Sachs estimates that the worldwide production capacity of lithium will increase at a rate of $12 \%$ compounded annual growth rate to meet demand from battery technologies through 2020, involving an increasing extraction from hard rock sources. ${ }^{54}$ The large amount of cobalt required is potentially even more worrying as the worldwide cobalt demand is being substantially sourced from the vast reserves in the Democratic Rep of Congo, ${ }^{55}$ a region of the world characterized by military conflict and significant human rights abuses upon workers, raising ethical issues as well as reliance issues. Graphite sourcing is currently dominated by China and it has equally raised ethical and environmental issues, although those are currently being at least partly addressed resulting also in reduced capacity. ${ }^{56}$ Advances in synthetic production of graphitic carbon may buffer the reliance on mined graphite in future. New cobalt and lithium ores are currentlybeing explored in less sensitive areas such as North America and Australia. Australia is certainly blessed with lithium and now cobalt ores, which places the country at the forefront of the battery raw material chain. ${ }^{57}$

In particular, as Tesla starts feeling the bottleneck of raw material sourcing in their supply chain and explores alternative sources of high purity lithium, a car maker from China, Great Wall, made a deal with a company in Western Australia for direct access of lithium ores. ${ }^{58}$ This is the first example of a car manufacturer securing directly raw materials for batteries, and indicates how securing the supply chain is fast becoming a crucial step.

Sourcing of battery raw materials from recycling is not realistic at the moment, as recycling of Li-ion batteries is yet in its infancy. Lithium-ion batteries are classified as Class 9 miscellaneous hazardous materials, and there are different challenges in terms of size, shape, complexity of the used materials, as well as the fact that recycling lithium from pyrometallurgical processes is not an energy- and cost-efficient process. ${ }^{59}$

\section{Power electronics and round-trip efficiency}

Every electron that flows into or out of the energy storage system must also traverse the power electronics, be that the battery management or PCSs. During the single cycle test of grid scale energy storage systems, it is not unusual for the measured round-trip efficiency of Li-ion based systems to be $75-80 \% .{ }^{60}$ A portion of this loss of energy is due to the batteries (2-15\%). ${ }^{61}$ However, much of it is also due to the power electronics, often $3-4 \%$ loss per charge or discharge. Compounding on these losses are the power needs to actively cool both the batteries and power electronics. These "balance of plant" losses, i.e., heating and cooling, have been observed to significantly reduce the overall efficiency of deployed energy storage system. In 2014, a study of Power New Mexico's Prosperity Electricity Storage Project's $500 \mathrm{~kW}$ PV system backed by $750 \mathrm{~kW}$ of battery storage (Fig. 2) observed that over a 12-month period, the average 


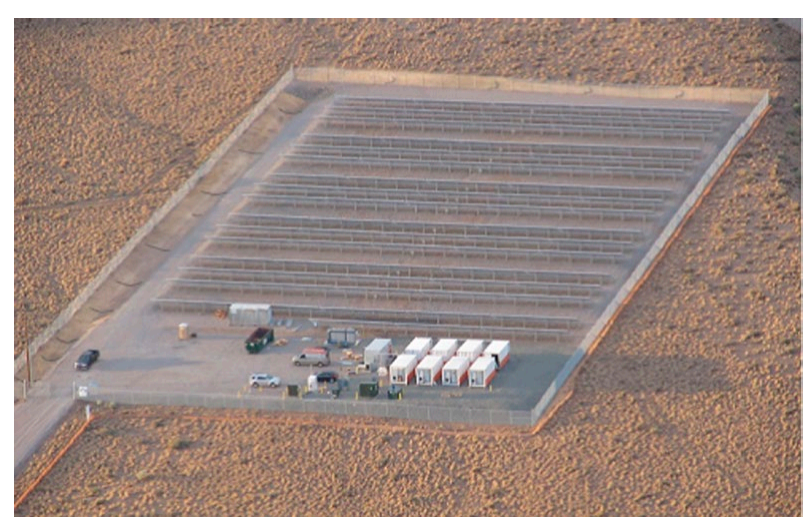

Figure 2. Aerial view of the Prosperity Electricity Storage Project in New Mexico, USA ${ }^{56}$ (reprinted with permission).

system round-trip efficiency (battery and power electronics) was $\mathbf{8 5 \%}$. However, when the balance of plant losses was included, the observed average round-trip efficiency dropped to $59 \% .{ }^{62}$ This points to the important need to increase the operating temperature windows of both the batteries as well as the power electronics, particularly when deployments are in regions where operating temperatures are in excess of $40{ }^{\circ} \mathrm{C}$, such as those that were encountered in the New Mexico desert and are routinely encountered in South Australia.

\section{Large-scale battery storage, climate goals, and energy security}

A rapid deployment of RE has been identified by the IPCC as crucial to meeting the deep decarbonization imperatives spelled out in the IPGG's 5th Assessment Report. The contribution of RE must be tripled or even quadrupled by 2050 . The scenarios modeled by the IPCC that succeed in limiting GHG concentrations to a 'safe' level of $450 \mathrm{ppm} \mathrm{CO}_{2 \mathrm{eq}}$ by 2050 are characterized by a tripling to nearly a quadrupling of the share of zero and low-carbon energy supply from renewables, in addition to other changes.

The Paris Agreement came into force in November $2016 .{ }^{63}$ Its target of holding average global warming to $2{ }^{\circ} \mathrm{C}$ with a view to $1.5^{\circ} \mathrm{C}$ is combined with a vaguely worded call for a shift to zero net emissions after 2050 requiring governments to rapidly decarbonize all sectors of economies. In particular, this will involve energy transition in the electricity generation, heating/ cooling, transport and industrial sectors. Rapid and deep decarbonization along the trajectories suggested at the pace required by science (i.e., more ambitious than pledges made so far under the Paris Agreement) will require large-scale implementation of energy storage technologies in addition to renewable electricity and RE generation. Countries do this by updating every five years their nonlegally binding Nationally Determined Contributions (NDCs) backed by necessary national and sub-national policy and law. ${ }^{64}$

Given this context, review of legal and policy frameworks at the international, domestic, and regional levels has a crucial but insufficiently examined role in ensuring the decarbonization of the energy sector through mechanisms such as RE storage based on large-scale batteries. There has been some success, during the past decade, with RE growing massively (up to tenfold in the case of PV) to become a mainstream aspect of electricity generation portfolios, and investment in electricity generation from RE sources is outstripping investment in fossil fueled electricity generation.

Many studies now indicate the technical feasibility of reaching $100 \%$ renewable electricity generation in various jurisdictions. ${ }^{65,66}$ Although deep decarbonization, however, may be technically feasible, often hasty assumptions are made about the ease of diffusion of RE technologies. These technical reports typically do not take sufficient account of the influence of law, policy, and economics in facilitating the uptake of new technologies.

Some legislatures have been slow to anticipate the changes associated with smart grid technologies. Early recognition of the issues was actually found in the United States, in the Energy Independence and Security Act (EISA) of $2007^{67}$ which identifies and describes ten aspects of a smart grid. One of these specifically mentioned in Part Seven "Deployment and integration of advanced electricity storage and peak shaving technologies" ${ }^{67}$

'Carbon lock-in' is a process whereby corporations invested in incumbent, highly profitable carbon-rich technologies have created direct and indirect subsidies and political pressures toward inertia and the failure to pick up options such as largescale batteries. ${ }^{68}$ Electricity laws in many nations give examples of 'carbon-lock in.' Under the Australian National Electricity $L a w$, for example, reliability, safety, and security are the dominant concepts (section "Winning the public relations battle"), leaving no room for the consideration of environmental factors, making it more difficult to adjust national level electricity law to achieve environmental protection objectives. By contrast in the United Kingdom under Sec. 3A(5) of the Electricity Act 1989 , the impact on the environment must be taken into account by decision makers. Likewise, the impact on the environment of public supply of electricity also must be considered in Germany under Sec. 1(1) of the Energy Act 2005.

Increased global uptake of BESS units directly answers 'carbon lock-in' opponents of RE who, as one lobbying strategy, propagate the myth that increasing levels of electricity production from renewable sources represent a threat to the security of supply of electricity due to the natural variability of sun and wind.

\section{Law and policy}

This section discusses and analyses examples of policies, laws, and regulations that are most relevant to supporting a rapid uptake of energy storage technologies.

\section{RE support laws}

There is a logical synergy between laws and policies that support and encourage RE investment, and subsequent decisions by actors to install variable RE storage technologies. The arrival 
at retail grid parity (i.e., competitiveness) under onshore wind and solar PV in a number of jurisdictions has given renewed impetus to campaigns to repeal or wind back laws that support projects such as RE feed-in tariffs. ${ }^{98}$

One important area of law and policy involves the insertion of large-scale batteries in a widely supported global public policy roadmap for transition to RE. One template could be the Storage Roadmap for California published by the CAISO California Independent System Operator. ${ }^{69}$ The California roadmap sets out 3 categories of priorities for storage policy: (i) Expanding revenue opportunities, (ii) Reducing costs of integrating and connecting to the grid, and (iii) Streamlining and spelling out policies and processes to increase certainty.

The rise of distributed energy sources such as solar photovoltaics, combined with large-scale battery storage, as well as convergence of these technologies with the internet, the smart grid and electric vehicles all represent challenges to incumbent 'archived photosynthesis' (oil, coal, and natural gas) companies in the electricity sector. The emergence of such new disruptive technologies raises questions of melding competition law to energy law. ${ }^{15}$ Competition law, for example, might be one mechanism for removing regulatory and cartel-like barriers to the entry of large-scale battery RE storage into the electricity market. ${ }^{16}$

\section{Grants and concessional loans}

One approach to encourage the uptake of large-scale storage technologies is to offer direct support in the form of grants and/ or loans on concessional terms. This is the approach in South Australia that has led to the installation of the Tesla battery, a $\$ 150$ million battery storage and renewable technology fund which is split 50/50 between grants and loans.

\section{Tax incentives}

The United States has applied the approach of giving a tax credit for investment in storage. The $20 \%$ Federal Investment Tax Credit (FITG) amends the Internal Revenue Code to allow, through 2020, a 20\% energy tax credit for investment in energy storage property that is directly connected to the electrical grid (i.e., a system of generators, transmission lines, and distribution facilities) and that is designed to receive, store, and convert energy to electricity, deliver it for sale, or use such energy to provide improved reliability or economic benefits to the grid. The law also makes such property eligible for new clean RE bond financing, allows a $30 \%$ energy tax credit for investment in energy storage property used at the site of energy storage; and allows a $30 \%$ nonbusiness energy property tax credit for the installation of energy storage equipment in a principal residence. ${ }^{70}$

Another example is the US Internal Revenue Code of 1986 which provides for an energy investment credit for energy storage property connected to the grid and provides the incentive for hydroelectric pumped storage and compressed air energy storage, regenerative fuel cells, batteries, superconducting magnetic energy storage, flywheels, thermal energy storage systems, and hydrogen storage, or combination thereof, with limits on hydro pumped storage and compressed air storage. ${ }^{71}$
The investment tax credit (ITC) is available in combination with the modified accelerated cost recovery system (MACRS) depreciation deduction where the installation is owned by a private party and not a public institution. ${ }^{72} \mathrm{~A}$ further bill to expand on available incentives, in the form of the Energy Storage Tax Incentive and Deployment Act of 2017 (S.1868) was introduced to Congress in September 2017. ${ }^{73}$ There are other aspects of tax law that can represent potential barriers to battery and other storage technologies that will need to be overcome.

\section{Modified feed in tariffs}

In Germany, in general, all technologies used to generate and store electricity from renewable sources are eligible for feed-in tariffs (§ 19 par. 1 EEG 2017). Eligibility also applies to electricity that was temporarily stored prior to being fed into the grid ( 19 par. 3 EEG 2017)."74 The Renewable Energy Sources Act (Erneuerbare-Energien-Gesetz EEG 2017) states that a feed-in tariff entitlement shall remain in place if the electricity has been placed in temporary storage before being fed into a grid system. In this case, the entitlement would refer to the quantity of electricity, that is, fed from the electricity storage system into the grid system. The level of the entitlement per fed-in kilowatt-hour shall be determined by the level of the entitlement which would have existed had the electricity been fed in without temporary storage. This entitlement also applies in the case of mixed use with storage gases. ${ }^{75}$ As another example, in the Australian Capital Territory auctions encourage energy storage by means of imposition of conditions on the winners of reverse auction process. ${ }^{76}$

\section{Storage mandates}

Legislation also can facilitate investment in battery storage and other energy storage technologies by mandating that electricity utilities bring within their portfolio a certain amount of MW of electricity storage. This approach has been quite successful in California since the passage of the Skinner Bill (Assembly Bill 2514) in 2010, and subsequent amendments. The California Public Utilities Commission in October 2013 adopted an energy storage procurement framework and an energy storage target of $1325 \mathrm{MW}$ for the Investor Owned Utilities (PG\&E, Edison, and SDG\&E) by 2020 , with installations required before 2025. ${ }^{77}$ Legislation can also permit electricity transmission or distribution companies to own generation assets (although this may concentrate market power), perhaps by ensuring that battery-stored energy is not defined as 'generated.'

A related approach supportive of BESS units is regulatory reform to retail electricity pricing and metering technologies toward a time-of-use pricing approach where battery systems are preferentially used at times of peak demand and associated higher retail prices. Such approaches help overcome two key barriers to the expansion of battery energy storage:

(i) "The lack of formal mechanism in electricity purchasing assessments carried out by the independent system operator (ISO) and utilities prevents the full value of 
energy storage from being captured, which distorts the perception of its costs and benefits";

(ii) The current cost advantages that incumbent actors in the energy sector enjoy, which are attributable to both the level of development and commercialization of storage technologies, and the uncertainty associated with costs. ${ }^{78}$

Large-scale battery storage would also be facilitated by new market rules that allow for the integration of energy storage resources in their ancillary market, i.e., markets for services that provide support to the electric grid's functionality rather than generation of electricity. The frequency-regulation ancillary services maintain system frequency within a safe range. 'Regulation' services correct for minor deviations in load or generation. 'Contingency' services correct the supply-demand balance following a major event such as the loss of a generator, transmission line, or major industrial customer. These services can be offered by generators and industrial loads with the ability to rapidly adjust output and are both considered ancillary services as they work to stabilize the grid.

\section{Time of use pricing or peak demand deferral incentives}

An indirect incentive for investment in large-scale battery storage is the introduction of time of use retail electricity pricing tariffs and/or incentives to defer demand at times of peak demand. If electricity pricing regimes do not reflect the actual cost of providing electricity at times of peak demand, there is a diminished price signal to install storage technologies at the home or commercial scale. This policy shifts expensive peaktime loads, such as cooling, to nonpeak times through energy storage devices. With only a flat rate charge for electricity, there is minimal incentive for customers to install their own storage devices. Electricity customers could obtain a discount based on the amount of peak kilowatts shifted to nonpeak times.

\section{Winning the public relations battle}

Despite the widespread adoption of national targets for installed RES-E generating capacity, at least in Australia, lobbyists for the fossil fuel ('archived photosynthesis') industries promote to government the notion that with the assistance of processes such as large-scale battery storage "too much" PV will be installed. ${ }^{79}$ This is coupled with the generalized and often debatable assumptions about renewable electricity being largely responsible for increases in retail electricity prices. In some jurisdictions at least, these assumptions are open to challenge.

Some of the responses of electricity distribution companies to distributed generation are based on technical concerns such as ensuring voltage quality, frequency control, and the unproven service life of the current generation of Li-ion batteries. However, with the rise of distributed generation and energy self-sufficiency, indeed the notion of 'grid defection' (coined by the Rocky Mountain Institute), ${ }^{80}$ there are new challenges for distributors and these may influence their approach and encourage greater reluctance to connect storage and RES-E quickly and as a priority.
Traditional electricity regulation is premised on legacy technologies and a one-way flow of electricity down the value chain from generator, through transmission and distribution to the retailer and on to the customer. However, with the ongoing rise of storage and smart grid technologies, there is an urgent need to reform electricity regulation and rules in most jurisdictions to adapt to the technological innovation. In brief, the issue raised by energy storage technologies is that of "regulatory adaptation to technological change. Advanced storage is a disruptive technology that confounds regulatory categories and market rules developed for legacy systems." 81

This lack of regulatory maturity plagued many of the sixteen energy storage demonstrations projects that were funded in the United States via the 2009 American Recovery and Reinvestment Act. ${ }^{82}$ These early projects faced challenges ranging from lack of regulations for sitting energy storage projects and their safety, to equitable market environments such as those described in the aforementioned Rocky Mountain Institute report.

Furthermore, use of big battery systems will be inhibited because RE storage, as such, does not have a universally accepted legal definition. If large scale battery storage systems, for example, are defined under law as 'consumers' of electricity stored into the storage system will be subject to several levies and taxes that are imposed on the consumption of electricity. Since the final recipient of the electricity, which has been fed from the storage system into the grid, is also a consumer, it may have to pay the same levies and taxes again. ${ }^{83}$

\section{Taking a holistic approach}

Despite the focus of this article on large-scale (grid-ready) battery energy storage technologies, it is apparent that to be successful, they will need to interact with a range of technologies that will be vital to manage the electricity grids as smarter grids that can more quickly, more flexibly, and more reliably match electricity supply and demand. As long ago as 2006 the United States Department of Energy (US DOE) defined the smart grid as involving automation and relying upon data capture and use, in fact as a "fully automated power delivery network that monitors and controls every consumer and node, ensuring a two-way flow of electricity and information." "84 Such technologies and strategies include advanced forecasting of supply, forecasting of demand on various different timescales, from day ahead to hour-ahead using neural networks. ${ }^{85}$ Some central features here include increased interconnection of electricity networks, more flexible conventional generation, increased balancing area cooperation and power to gas technologies including hydrogen.

Whilst storage focuses on the supply side of the equation, it is vital that policy makers considering the role of large-scale batteries also reflect on the important role that policy and legislation have to encouraging the uptake of modern demand side management tools, and demand side response aggregation technologies. ${ }^{86}$ More broadly, the disruptive implication of other technologies will inevitably have an impact on the management of electricity networks of the future. This is why 
scholars have already begun to discuss and analyze the implications of artificial intelligence technologies as a part of the modern smart grid, as an aid to more automated grid and network management. ${ }^{87-89}$

Equally important will be facilitating progress in a variety of different scientific and technological fields such as wide band gap semiconductor technologies for power electronics, such as devices, integration processes, packaging, and reliability. ${ }^{39}$ Undoubtedly, progress in nanotechnology and nanostructured materials will underpin many future processes in batteries and energy storage technologies, as leading to more controlled and optimized ionic and electronic transport and larger surfaceto-volume ratios, improving the efficiency of most processes included in a Li-ion battery charge/discharge cycle. Research at the cross section of nanomaterials and electrochemistry will enable the energy storage research community to push the boundaries of the lifetime and power densities of Li-ion batteries. Advances improving calendar and cycle life would relax the periodical need for large quantity of rare materials to replace old batteries. In addition, useful alternatives to the use of lithium cobalt oxide cathode materials (such as lithium manganese oxide) should be strongly encouraged.

Likewise, continuing to expand the horizon beyond Li-ion technologies at large is vital. Metal-air and metal-sulfur approaches, still using lithium as the charge carrier, hold promise of obtaining higher energy densities for a lesser quantity of lithium. Further research into Na-ion batteries could result in comparable energy densities using a much more prevalent raw material and safer battery operation. Perhaps the push in the long term should be toward the discovery of a completely new electrochemical storage technology in the way Li-ion has revolutionized the current landscape. Flow batteries may prove to be an option. ${ }^{90}$

Non-Faradaic complementary alternatives to batteries should also be contemplated, such as supercapacitors. ${ }^{91}$ Supercapacitors can show lifetimes substantially longer than batteries, relying to a lesser extent on redox processes (pseudo-capacitors) or not at all (double-layer capacitors), and involving no phase transformations. Supercapacitors lifetimes, safety, and power delivery are all superior to batteries, and in addition, they do not need rare materials but are commonly based on carbon electrodes, although they cannot yet compete in terms of energy densities. ${ }^{92}$ One way to combine the advantages of supercapacitors and batteries is the development of hybrid electrochemical structures or cells to cover the right-hand quadrant of the Ragone plot (Fig. 1), maximizing energy and power densities. ${ }^{93}$

As a final consideration, policies should also consider and encourage the use of large-scale batteries as transition agents for radically different RE system solutions with positive environmental implications. For example, artificial photosynthesis (on many approaches the use of nanotechnology to facilitate solar energy storage in chemical bonds) could become an additional powerful RE resource. Globalizing artificial photosynthesis offers the prospect of every road and building on the earth's surface making clean fuel, food and fertilizer just from water, sun, and air, as well as assisting ecosystem sustainability, a hypothetical policy era of eco-centric governance ("Sustainocene" ). ${ }^{94,95}$ The production of hydrogen by solar-driven water splitting is one visionary strategy in artificial photosynthesis as is reduction of carbon dioxide. ${ }^{96}$ At the moment lithiumion batteries are more efficient in terms of energy density than hydrogen, though more environmentally deleterious. It is likely long-term that improved batteries will shift in design toward facilitating electrolysis (solar-driven or electricitydriven water splitting). ${ }^{97}$ Policy and regulation needs to be ready to move with this transition in governmental commitments to limit the adverse consequences of anthropogenic climate change.

\section{Conclusion}

Policy makers and regulators around the world are confronted with the disruptive implications of energy storage technologies, both at large capacity scale and distributed microscale installations. Large-scale battery storage technologies can be a practical way to maximize the contribution of variable renewable electricity generation sources (particularly wind and solar). In doing so, they facilitate a nation's ability to rapidly meet national and sub-national decarbonization targets as well as national contributions under the Paris Agreement, whilst maintaining stability and security energy supply. As discussed in this review, there are still numerous challenges associated with the integration of large-scale battery energy storage into the electric grid. These challenges range from scientific and technical issues, to policy issues limiting the ability to deploy this emergent technology, and even social challenges.

The large-scale BESS facility recently installed in Hornsdale, South Australia, represents a unique test case, informing future approaches in technical, economic, and policy fields. Continued encouragement of fundamental research in large-scale battery research necessarily will focus on enhancing efficiency and reliability as well as the transition to even more globally efficient and environmentally protective RE generation and storage technologies.

\section{Acknowledgments}

This work was partly performed, in part, under Australian Research Council Grant No. DP140100566 and at the Center for Integrated Nanotechnologies, an Office of Science User Facility operated for the U.S. Department of Energy (DOE) Office of Science. Sandia National Laboratories is a multi-mission laboratory managed and operated by National Technology and Engineering Solutions of Sandia, LLC., a wholly owned subsidiary of Honeywell International, Inc., for the U.S. Department of Energy's National Nuclear Security Administration under contract DE-NA-0003525.

\section{NOTES AND REFERENCES:}

1. REN 21 GSR global status report: Available at: http://www.ren21.net/ wp-content/uploads/2017/06/17-8399_GSR_2017_Full_Report_0621_ Opt.pdf. pp137 et seqq (accessed July 26, 2018).

2. Faunce T.A. and Charles C.: Nanotechnology, plasma, hydrogen from artificial photosynthesis and fuel cells: Powering the developing world to the sustainocene. In Nanotechnology Toward the Sustainocene, Faunce T.A., ed. (Pan Stanford, Singapore, 2015); pp. 241-253. 
3. UN Paris Agreement, status of ratification update: Availabe at: http:// unfccc.int/paris_agreement/items/9444.php (accessed November 6, 2017).

4. International Energy Agency: Tracking clean energy report, 2017.

5. REN 21 global renewables report: Available at: http://www.ren21. net/future-of-renewables/global-futures-report/ (accessed July 26 , 2018).

6. International Energy Agency IEA: Technology Roadmap: Energy Storage (2014); p. 26.

7. Ferrey S.: Efficiency in the regulatory crucible: Navigating 21st century smart technology and power. Geo. Wash. J. Energy Environ. Law 1, 32 (2012).

8. International Energy Agency IEA: Tracking progress: Energy storage (2017). Available at: http://www.iea.org/etp/tracking2017/energystorage/ (accessed July 26, 2018).

9. IEA: Tracking clean energy progress 2017: Energy technology perspectives 2017 (2017). Available at: http://www.iea.org/etp/tracking2017/ energystorage/ (accessed July 26, 2018).

10. IEA 2017 at 62 : Aavailable at: http://www.iea.org/publications/ freepublications/publication/TrackingCleanEnergyProgress2017.pdf (accessed July 26, 2018).

11. Edenhofer O., Pichs-Madruga R., Sokona Y., et. al., eds.: Renewable Energy Sources and Climate Change Mitigation: Special Report of the Intergovernmental Panel on Climate Change (Cambridge University Press, 2011).

12. Australian Energy Regulator: State of the Energy Market: May 2017 (2017); p. 158. Available at: https://www.aer.gov.au/publications/state-of-theenergy-market-reports/state-of-the-energy-market-may-2017 (accessed July 26, 2018).

13. Clean Energy Council: Clean Energy Report Australia, 2016. Available at: https://www.cleanenergycouncil.org.au/policy-advocacy/reports/ clean-energy-australia-report.html (accessed July 26, 2018).

14. Australian Energy Market Operator (2017) South Australia: System Black Report (4th and Final), March 2017, 271pp. Available at: https:// www.aemo.com.au/-/media/Files/Electricity/NEM/Market_Notices_ and_Events/Power_System_Incident_Reports/2017/Integrated-FinalReport-SA-Black-System-28-September-2016.pdf (accessed July 26, 2018).

15. Turnbull ignored advice that renewable energy not to blame for SA blackouts. Available at: https://www.theguardian.com/australianews/2017/feb/13/turnbull-ignored-advice-that-renewable-energy-not-toblame-for-sa-blackouts (accessed July 26, 2018).

16. Lloyd G.: 'Can South Australia battery power Elon musks' Tesla dreams? Weekend Australia July 15, 2017.

17. Elon Musk's giant lithium ion battery completed by Tesla in SA's Mid North. Available at: http://www.abc.net.au/news/2017-11-23/ worlds-most-powerful-lithium-ion-battery-finished-in-sa/9183868 (accessed July 26, 2018).

18. Elon Musk Tesla to give solar panel batteries to SA homes. ABC news. Available at: http://www.abc.net.au/news/2018-02-04/elon-musktesla-to-give-solar-panels-batteries-to-sa-homes/9394352 (accessed July 26, 2018).

19. Blood D.: Battery-based energy storage: The renewable power proliferation enabler. Renewable Energy Focus 17(6), 237-310 (2016).

20. DOE global energy storage database. Available at: http:// energystorageexchange.org/projects/2217 (accessed July 26, 2018).

21. Haegel N.M., Margolis R., Buonassisi T., Feldman D., Froitzheim A., Garabedian R., Green M., Glunz S., Henning H., Holder B., Kaizuka I., Kroposki B., Matsubara K., Niki S., Sakurai K., Schindler R.A., Tumas W., Weber E.R., Wilson G., Woodhouse M., and Kurtz S.: Terawatt-scale photovoltaics: Trajectories and challenges. Science 356(6334), 141-143 (April 14, 2017). Available at: https://doi.org/10.1126/science.aal1288.

22. Denholm P., O'Connell M., Brinkman G., and Jorgenson J.: Overgeneration from solar energy in California: A field guide to the duck chart" national renewable energy laboratory. Prepared under Task No. TM13 5020. Available at: https://www.nrel.gov/docs/fy16osti/65023.pdf (accessed July 26, 2018).
23. Hongwei Y., Duan J., Du W., Xue S., and Sun J.: China's energy storage industry: Develop status, existing problems and countermeasures. Renewable Sustainable Energy Rev. 71, 767-784 (2017).

24. Ning Z., Lu X., McElroy M.B., Nielsen C.P., Chen X., Deng Y., and Kang C.: Reducing curtailment of wind electricity in China by employing electric boilers for heat and pumped hydro for energy storage. Appl. Energy 184, 987-994 (2016).

25. Kunisch H.J., Kramer K.G., and Dominik H.: Battery energy storageanother option for load-frequency-control and instantaneous reserve. IEEE Trans. Energy Convers. 1, 41-46 (1986).

26. Naser W.: New frequency regulation in Berlin. Elektrizitatswirtschaft $\mathbf{8 6}$, 532-535 (1987).

27. Sossan F. and Paolone M.: Integration and operation of utility-scale battery energy storage systems: The EPFL's experience. IFAC-Papers on Line 49-27, 433-438 (2016).

28. Change B., Kim C., Kim T., Jeon W., Shin S., and Han H.: Demonstration study on the large-scale battery energy storage for renewables integration. Energy Environ. 26(1), 183-194 (2015).

29. Khald M. and Savkin A.: Model predictive control based efficient operation of battery energy storage system for primary frequency control. In 11 th International Conference on Control Automation Robotics and Vision (2010); pp. 2248-2252.

30. Sigrist L., Lobato E., and Rouco L.: Energy storage systems providing primary reserve and peak shaving in small isolated power systems: An economic assessment. Int. J. Electr. Power Energy Syst. 53, 675-683 (2013).

31. Reihani E., Sepasi S., Roose L.R., and Matsura M.: Energy management at the distribution grid using a battery energy storage system (BESS). Electr. Power Energy Syst. 77, 337-344 (2016).

32. Stenzel P., Koj J.C., Schreiber A., Hennings W., and Zapp P.: Primary control provided by large-scale battery energy storage systems or fossil power plants in Germany and related environmental impacts. J. Energy Storage 8, 300-310 (2016).

33. Koj J.C., Stenzel P., Schreiber A., Hennings W., Zapp P., Wrede G., and Hahndorf I.: Life cycle assessment of primary control provision by battery storage systems and fossil power plants. Energy Procedia 73, 69-78 (2015).

34. Blomgren G.E.: The development and future of lithium ion batteries. J. Electrochem. Soc. 164(1), A5019-A5025 (2017).

35. Choi J.W. and Aurbach D.: Promise and reality of post-lithium-ion batteries with high energy densities. Nat. Rev. 1(1), 1-16 (2016).

36. Whittingham M.S.: Electrical energy storage and intercalation chemistry. Science 192(4244), 1126-1127 (1976).

37. Roth E.P. and Orendorff C.J.: How electrolytes influence battery safety. Electrochem. Soc. Interface 21(2), 45-49 (2012).

38. McCloskey B.D.: Expanding the Ragone plot: Pushing the limits of energy storage. J. Phys. Chem. Lett. 6, 3592-3593 (2015).

39. Iacopi F., Van Hove M., Charles M., and Endo K.: Electronics with wide bandgap materials: Towards greener, more efficient technologies. Mater. Res. Bull. 40(5), 390-395 (2015).

40. Kucinskis G., Bajars G., and Kleperis J.: Graphene in lithium ion battery cathode materials: A review. J. Power Sources 240, 66-79 (2013).

41. Yang T.C-J., Fiala P., Jeangros Q., and Ballif C.: High-bandgap Perovskite materials for multijunction solar cells. Nat. Energy 2, 861-868 (2017).

42. Bucur C.B., Gregory T., Oliver A.G., and Muldoon J.: Confession of a magnesium battery. J. Phys. Chem. Lett. 6, 3578-3591 (2015).

43. Jayaprakash N., Das S.K., and Archer L.A.: The rechargeable aluminumion battery. Chem. Commun. 47, 12610-12612 (2011).

44. Ji X., Lee K.T., and Nazar L.F.: A highly ordered nanostructured carbon-sulphur cathode for lithium-sulphur batteries. Nat. Mater. 8 , 500-506 (2009); J. Zheng et al:. ACS Energy Lett. 2(5), 1105-1114 (2017).

45. Tułodziecki M., Leverick G.M., Amanchukwu C.V., Katayama Y., Kwabi D.G., Bardé F., Hammond P.T., and Shao-Horn Y.: The role of iodide in the formation of lithium hydroxide in lithium-oxygen batteries. Energy Environ. Sci. 8, 10 (2017).

46. Wang W., Luo Q., Li B., Wei X., Li L., and Yang Z.: Recent progress in redox flow battery research and development. Adv. Funct. Mater. 23(8), 970-986 (2013). 
47. Simon P. and Gogotsi Y.: Materials for electrochemical capacitors. Nat. Mater. 7, 845 (2008).

48. Vetter J., Novak P., Wagner M.R., Veit C., Möller K-C., Besenhard J., Winter M., Wohlfahrt-Mehrens M., Vogler C., and Hammouce A.: Ageing mechanisms in lithium-ion batteries. J. Power Sources 147, 269-281 (2005).

49. Blomgren G.E.: J. Electrochem. Soc. 164(1), A5019-A5025 (2017).

50. Li L., Wang P., Chao K-H., Zhou Y., and Xie Y.: Remaining useful life prediction for lithium ion batteries Based on Gaussian processes mixture. PLoS One 11(9), e0163004 (2016).

51. AS/NZS 5139 electrical installations: Safety of battery systems for use with power conversion equipment, 2017. Available at: https://sapc.standards. org.au.

52. Zakeri B. and Syri S.: Electrical energy storage systems: A comparative life cycle cost analysis. Renewable Sustainable Energy Rev. 42, 569-596 (2015).

53. Wired: Can This Tesla Alum Build the World's Greenest Battery? Available at: https://www.wired.com/story/ev-green-battery-factory-in-thenetherlands-competes-with-the-gigafactory/ (accessed July 26, 2018).

54. Goldman Sachs: Low Carbon Economy Report (Goldman Sachs, New York, 2016).

55. US Geological Survey: World cobalt reserves as of 2017, by country (in metric tons) (n.d.). Available at: https://www.statista.com/ statistics/264930/global-cobalt-reserves/ (accessed July 26, 2018).

56. Yanga Q., Geng Y., Dong H., Zhang J., Yue X., Sunf L., Lug X., and Chen Y.: Effect of environmental regulations on China's graphite export. J. Clean. Prod. 161, 327-334 (2017).

57. US department of interior, US geological survey, mineral commodities, 2018, Available at: https://minerals.usgs.gov/minerals/pubs/mes/2018/ mcs2018.pdf (accessed July 26, 2018).

58. China's Great Wall Secures Lithium Supply Reuters, 2017. Available at: https://www.reuters.com/article/us-great-wall-motor-pilbara/chinasgreat-wall-secures-lithium-supply-with-pilbara-deal-idUSKCN1C40JY (accessed July 26, 2018).

59. Gaines L.: The future of automotive lithium-ion battery recycling: Charting a sustainable course. Sustainable Mater. Technol. 1-2, 2-7 (2014).

60. Rose D.M., Schenkman B., and Borneo D.: SANDIA REPORT SAND20138849 (US Department of Energy Sandia Laboratories, Albuquerque, New Mexico, 2013).

61. Fernão Pires V., Romero-Cadaval E., Vinnikov D., Roasto I., and Martins J.F.: Power converter interfaces for electrochemical energy storage systems-A review. Energy Convers. Manage. 86, 453-475 (2014).

62. Roberson D., Ellison J.F., Bhatnagar D., and Schoewald D.A.: SANDIA REPORT SAND2014-2883 (US Department of Energy Sandia Laboratories, Albuquerque, New Mexico, 2014).

63. Bodansky D., Brunnée J., and Rajamani L.: International Climate Change Law, 1st ed. (Oxford University Press, Oxford, U.K., 2017); p. 209. Made at the 21st Conference of the Parties to the UNFCCC meeting in Paris, 12 December 2015, the Paris Agreement entered into force on 4 November 2016, and has 195 Signatories: 195. A large proportion of this, $86.1 \%$, i.e., 168 nations have now officially become Parties to the Paris Agreement.

64. The World Bank has compiled a freely accessible database of NDCs. Available at: http://spappssecext.worldbank.org/sites/indc/Pages/ INDCHome.aspx (accessed July 26, 2018).

65. Jacobson M.Z., Delucchi M.A., Bauer Z.A.F., Goodman S.C., Chapman W.E., Cameron M.A., Bozonnat C., Chobadi L., Clonts H.A., Enevoldsen P., Erwin J.R., Fobi S.N., Goldstrom O.K., Hennessy E.M., Liu J., Lo J., Meyer C.B., Morris S.B., Moy K.R., O’Neill P.L., Petkov I., Redfern S., Schucker R., Sontag M.A., Wang J., Weiner E., and Yachanin A.S.: 100\% clean and renewable wind, water, and sunlight (WWS) all-sector energy roadmaps for 139 countries of the world. Joule 1, 108-121 (2017). Available at: http://www.cell.com/joule/pdf/S2542-4351(17)30012-0.pdf (accessed July 26, 2018).

66. Jacobson M.Z., Delucchi M.A., Bazouin G., Bauer Z.A.F., Heavey C.C., Fisher E., Morris S.B., Piekutowski D.J.Y., Vencill T.A., and Yeskoo T.W.: $100 \%$ clean and renewable wind, water, and sunlight (WWS) all-sector energy roadmaps for the 50 United States. Energy Environ. Sci. 8(7), 2093 (2015).
67. Energy Independence and Security Act (EISA) of $200^{\prime} \S 1301,42$ U.S.C. § 17,381 (Supp. I 2007)

68. Unruh G.: Understanding carbon Lock-in. Energy Policy 28, 817-830 (2000). Unruh G.: Escaping carbon lock-in. Energy Policy 30, 317-325 (2002).

69. CAISO: Advancing and Maximizing the Value of Energy Storage Technology: A California Roadmap (2014). Available at: https://www. caiso.com/informed/Pages/CleanGrid/EnergyStorageRoadmap.aspx (accessed July 26, 2018).

70. Storage 2011 Act: Available at: https://www.congress.gov/bill/112thcongress/senate-bill/1845 (accessed July 26, 2018).

71. Storage 2011 Act: https://www.congress.gov/bill/112th-congress/ senate-bill/1845/text (accessed July 26, 2018).

72. NREL: Federal Tax Incentives for Battery Storage Systems (2018). Available at: https://www.nrel.gov/docs/fy18osti/70384.pdf (accessed July 26, 2018).

73. Energy Storage Tax Incentive and Deployment Act. Available at: https:// www.congress.gov/bill/115th-congress/senate-bill/1868?r=1 (accessed July 26, 2018).

74. Feed In Tariff: Legal Sources on Renewable Energy. Available at: http:// www.res-legal.eu/search-by-country/germany/single/s/res-e/t/promotion/ aid/feed-in-tariff-eeg-feed-in-tariff/lastp/135/ (accessed July 26, 2018).

75. Gesetz für den Ausbau erneuerbarer Energien (Erneuerbare-EnergienGesetz - EEG, 2017). Available at: https://www.gesetze-im-internet.de/ eeg_2014/BJNR106610014.html (accessed July 26, 2018). Renewable Energy Sources Act (EEG 2017). Available at: https://www.clearingstelleeeg-kwkg.de/files/node/8/EEG_2017_Englische_Version.pdf (accessed July 26, 2018).

76. Next generation renewables ACT government: Available at: https://www. environment.act.gov.au/energy/cleaner-energy/next-generationrenewables (accessed July 26, 2018).

77. AB2514 was approved on september 29, 2010 and was entered into California public utilities code, chapter 7.7, sections 2835-2839; CPUC decision D14-10-045, October 16, 2014.

78. Elkind E.N., Weissman S., and Hecht S.: The Power of Energy Storage: How to Increase Deployment in California to Reduce Greenhouse Gas Emissions (Policy Paper, Center for Law, Energy \& the Environment, UC Berkeley School of Law and Environmental Law Center \& Emmett Center on Climate Change and the Environment, UCLA School of Law, July 2010); p. 3.

79. Parkinson G.: Why Generators Are Terrified of Solar, 26 March 2012. Available at: http://reneweconomy.com.au/2012/why-generators-areterrified-of-solar-44279 (accessed July 26, 2018).

80. Rocky Mountain Institute, Homer Energy, and Cohnreznick Think Energy: The Economics of Grid Defection: When and where Distributed Solar Generation Plus Storage Competes with Traditional Utility Service.

81. Meyer A.H.: Federal regulatory barriers to grid-deployed energy storage, 39 colum. J. Envtl. L. 479, 557 (2014); at 539.

82. Bender D., Byrne R., and Borneo D.: ARRA Energy Storage Demonstration Projects: Lessons Learned and Recommendation, Sandia National Laboratories, SAND2015-5242, 2015.

83. Energy Storage in Germany. Norton, Rose Fulbright: Available at: http://www.nortonrosefulbright.com/knowledge/publications/147129/ energy-storage-in-germany-what-you-should-know (accessed July 26, 2018).

84. Title XIII of the Energy Independence and Security Act of 2007 (EISA) which gave legislative support for DOE's smart grid activities.

85. Senjyu T., Takara H., Uezato K., and Funabashi T.: One-hour-ahead load forecasting using neural network. IEEE Trans. Power Syst. 17(1), 113-118 (2002).

86. Brophy H.A., Jamasb T., Platchkov L.M., and Pollitt M.G.: Demand-side management strategies and the residential sector: Lessons from the international experience. In The Future of Electricity Demand, Jamasb T. and Pollitt M., eds. (Cambridge University Press, Cambridge, 2011); pp. 337-378.

87. Sarvapali R.D., Vytelingum P., Rogers A., and Jennings N.R.: Putting the 'smarts' into the smart grid: A grand challenge for artificial intelligence. Commun. ACM 55(4), 86 (2012). 
88. Valentin Robu why artificial intelligence could be key to future-proofing the grid. The Conversation, January 28, 2017.

89. Liu D., Pang J., Zhou J., Peng Y., and Pecht M.: Prognostics for state of health estimation of lithium-ion batteries based on combination Gaussian process functional regression. Microelectron. Reliab. 53(6), 832-839 (2013).

90. Gary Yang Z.: It's Big and Long-Lived, and it Won't Catch Fire: The Vanadium Redox-flow Battery (IEEE Spectrum Magazine, New York, 2017)

91. Demming A.: Supercapacitors empower sustainable energy storage. Nanotechnology 27, 250201 (2016).

92. Ahmed M., Wang B., Gupta B., Boeckl J.L., Motta N., and Iacopi F.: On-silicon supercapacitors with enhanced storage performance. J. Electrochem. Soc. 164(4), A638-A644 (2017).

93. Zuo W.H., Li R.Z., Zhou C., Li Y.Y., Xia J.L., and Liu J.P.: Batterysupercapacitor hybrid devices: Recent progress and future prospects. Adv. Sci. 4, 1600539 (2017).
94. Faunce TA Global Artificial Photosynthesis: Transition from corporatocene to sustainocene. Photochemistry 44, 261-284 (2017).

95. Faunce T.A., Styring S., Wasielewski M.R., Brudvig G.W., Rutherford A.W., Messinger J., Lee A.F., Hill C.L., deGroot H., Fontecave M., MacFarlane D.R., Hankamer B., Nocera D.G., Tiede D.M., Dau H., Hillier W., and Wang A.R.: Artificial photosynthesis as a Frontier technology for energy sustainability. Energy Environ. Sci. 6, 1074-1076 (2013).

96. Liu C., Colon B.C., Ziesack M., Silver P.A., and Nocera D.G.: Water splitting-biosynthetic system with $\mathrm{CO}_{2}$ reduction efficiencies exceeding photosynthesis. Science 352(6290), 1210-1213 (2016).

97. Moliner R., Lazaro M.J., and Suelves I.: Analysis of the strategies for bridging the gap towards the hydrogen economy. Int. J. Hydrogen Energy 44, 19500-19508 (2016).

98. Prest J.: The future of feed-in tariffs: Capacity caps, scheme closures and looming grid parity. Renew. Energy Law Policy Rev. 3(1), 25-41 (2012). 